\title{
Transnasal oesophagoscopy - A study of its advantages and limitations
}

\author{
M. K. Gupta ${ }^{1}$, Manisha Upadhya ${ }^{2, *}$, Anand Bihari ${ }^{3}$ \\ ${ }^{1,2}$ Associate Professor, ${ }^{3}$ Assistant Professor, Dept. of ENT, Government Medical College and Super Facility Hospital, Azamgarh, Uttar \\ Pradesh, India
}

*Corresponding Author: Manisha Upadhya

Email: manishup73@gmail.com

\begin{abstract}
Transnasal oesophagoscopy is a convenient method for doing oesophagoscopy. It is done by a thin 5.9 mm diameter flexible endoscope through nasal passage. ${ }^{1}$ Patient tolerates this procedure very well. No sedation is required for this procedure. Only nose is anaesthetized locally by xylocaine $2 \%$, and decongested by xylometazoline. No xylocaine sray is needed for throat, as some patients do not tolerate is throat numbness and feel dyspnic. ${ }^{2}$ TNE procedure takes shorter time and alleviates the diagnostic delay. This procedure can be done for diagnosing various pathologies of oesophagus, can be used for screening of barrate, s oesophagus. Biopsy can be done easily by $2 \mathrm{~mm}$ channel.
\end{abstract}

Keywords: TNE, Unsedated endoscopy, Transoral endoscopy.

\section{Introduction}

TNE was developed first by Jonathan E Aviv, who published his findings in year $2000 .^{2}$ Since then this procedure is being widely used world wide for diagnostic and therapeutic purposes. This procedure requires no sedation. No gag reflex is found in this procedure. Patients tolerate this procedure very well. ${ }^{3}$ Otolaryngologists are better versed with nasal anatomy, and and can do TNE procedure with ease. Patients acceptability to this procedure is amazing. Repeat procedure is easily accepted by patients. Trans oral endoscopy needs sedation and is done by $10 \mathrm{~mm}$ thick endoscope, which very much distressing to patient.

\section{Materials and Methods}

This study on TNE was done in GMC azamgarh on 100 patients of dysphagia and other aerodigestive disorders. TNE was done by fujinon transnasal oesophagoscope GE530 NW and processor ed 4400 hd. Patients were also subjected to transoral endoscopy on consecutive days. They were given a questionarre (visual analogue scale) to acess the tolerability of the procedure, and the results were compared.

\section{Anatomy and Technique}

Since the the is passed through nasl cavity, its anatomy is important. Nasal septum, inferior and middle turbinate are visualized. Deviation of nasal septum causes narrowing of other side. Scope can be passed between inferior and middle turbinate, or along the floor of nose medial and inferior to inferior turbinate. ${ }^{4}$ Auther prefers the latter method. Some times obstruction is at the level of posterior choana by spur. A little force is applied to scope to endoscpe to enter the nasal passage. Nasal anatomy is inspected with nasal speculum and headlight by otolaryngologist. DNS, spur and inf turbinate hypertrophy is noted. More patent side of nostril is selected. A patty with $2 \%$ xylocaine and xylometazoline is packed in the selected nostril. After 10 mts the patty is removed. There is no need of applying xylocaine jelly as it may block the nozzle of air water channel. There is no need to apply xylocaine spray in throat as some patients become uncomfortable with the numb throat and may panic. $5.9 \mathrm{~mm}$ thin endoscope is passed in nostril after removing patty in sitting position, or left lateral position. ${ }^{4}$ Auther prefers sitting position.

Nasal cavity, nasopharynx, torus tubarus, eustachian tubal opening, pharynx and laryngeal mobility is all inspected and recorded. Then the thin endoscope is advanced in pyriform fossa and patient is asked to swallow the saliva. With swallowing the endoscope is advanced in oesophagus. If the pt is apprehensive, he may be given small amount of water by sraw to swallow. With adavancement of oesophagus, the lumen of oesophagus is opened by air insufflations. The lumen is inspected thoroughly. At the gastroesophageal junction, patient is asked to pronounce word gey. This helps in opening the gastroesophageal junction. Endoscope is passed in stomach and with $j$ manouvere the junction is inspected from below for hiatus hernia. Anatomy of oesophagus - oesophagus is a muscular tube consisting of both skeletal and smooth muscle fibres. Oesophagus has three primary constrictions, at the level of aorta, left main bronchus and diaphragmatic hiatus. Sqamocolumner junction is the junction between oesophageal mucosa and stomach mucosa. Gastroesophageal junction is marked by termination of linear oesophageal mucosal vessels from above and termination of gastric rouge from below. Normally the SCJ and GEJ lie at the level of diaphragmatic hiatus. Gastric rouge may normally extend up to $2 \mathrm{~cm}$ above diaphragmatic hiatus. If the SCJ extends beyond the GEJ, it suggests presence of barrets oesophagus. ${ }^{5,6}$ If the GEJ, ie. termination of gastric rouge extends more than $2 \mathrm{~cm}$ from diaphragmatic hiatus, it suggests hiatus hernia. ${ }^{7-9}$

\section{Observation}

Out of 100 pts examined 48 were male and 52 were female. 2 patients were below the age of 10 years, 12 patients were in age group of 11 to 20 years, 25 patients were in age group of 21 to 30 years, 31 patients were in age 
group of 31 to 40 yers, and 30 patients were in the age group above 40 years. Out of 100 pts examined by the method, two were diagnosed as a case of growth oesophagus, 5 as a cse of benign stricture oesophagus, 32 pts showed reflux oesophagitis of various grades, 10 pts of achalasia cardia, 5 pts of oesophageal diverticulum, 8 pts of hiatus hernia, 12 pts of barrett,s oesophagus, $6 \mathrm{pt}$ of candidial oesophagitis, and rest were normal. In our study, out of 100 pts undergoing tne, $4 \%$ pts sufferd epistaxix, $2 \%$ pts suffered vasovagal syncope, $2 \%$ pts sufferd gagging and vomiting. In $6 \%$ patients endoscope could not be passed through nasal route because of obstruction, and endoscopy was done through oral route in these patients.

Table 1: Male Female Ratio

\begin{tabular}{|c|c|}
\hline Sex & Patient \\
\hline Male & 48 \\
\hline Female & 52 \\
\hline
\end{tabular}

Table 2: Age Distribution

\begin{tabular}{|c|c|}
\hline Age Group & Number of patients \\
\hline $0-10$ & 2 \\
\hline $11-20$ & 12 \\
\hline $21-30$ & 25 \\
\hline $31-40$ & 31 \\
\hline$>40$ & 30 \\
\hline
\end{tabular}

Table 3: Disease Distribution

\begin{tabular}{|l|c|}
\hline \multicolumn{1}{|c|}{ Disease } & Disease and number of Patients \\
\hline Growth Oeso & 2 \\
\hline Stricture & 5 \\
\hline Reflux oeso & 32 \\
\hline Achalasia & 10 \\
\hline Diverticulum & 5 \\
\hline Hiatus hernia & 8 \\
\hline Barretts & 12 \\
\hline Candidial Oeso & 6 \\
\hline
\end{tabular}

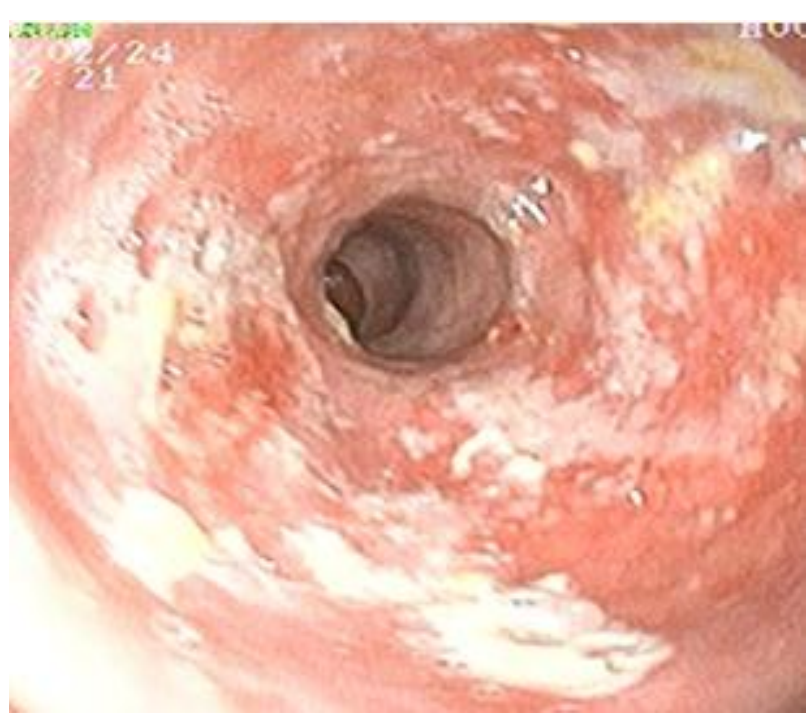

Fig. 1: Reflux Oesophagitis

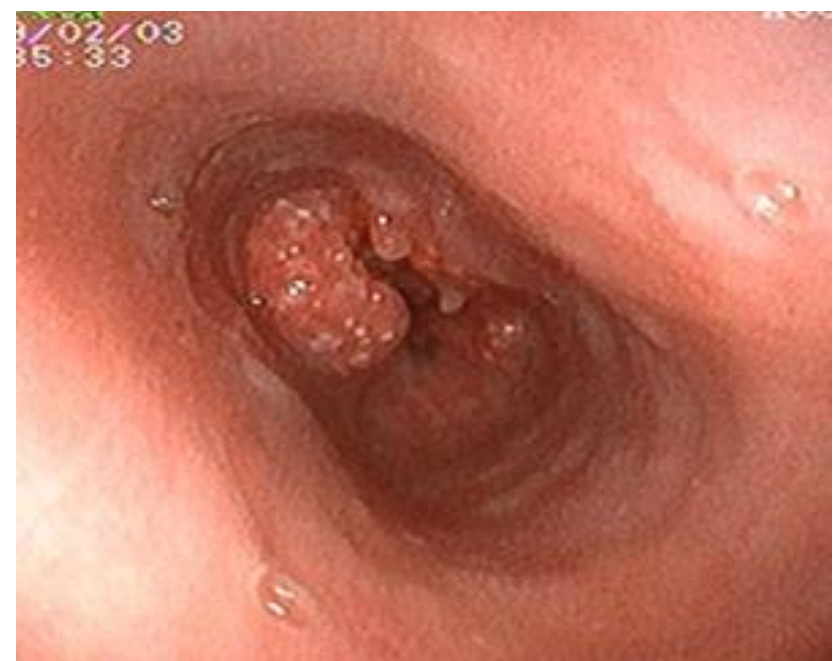

Fig. 2: Growth Oesphagus

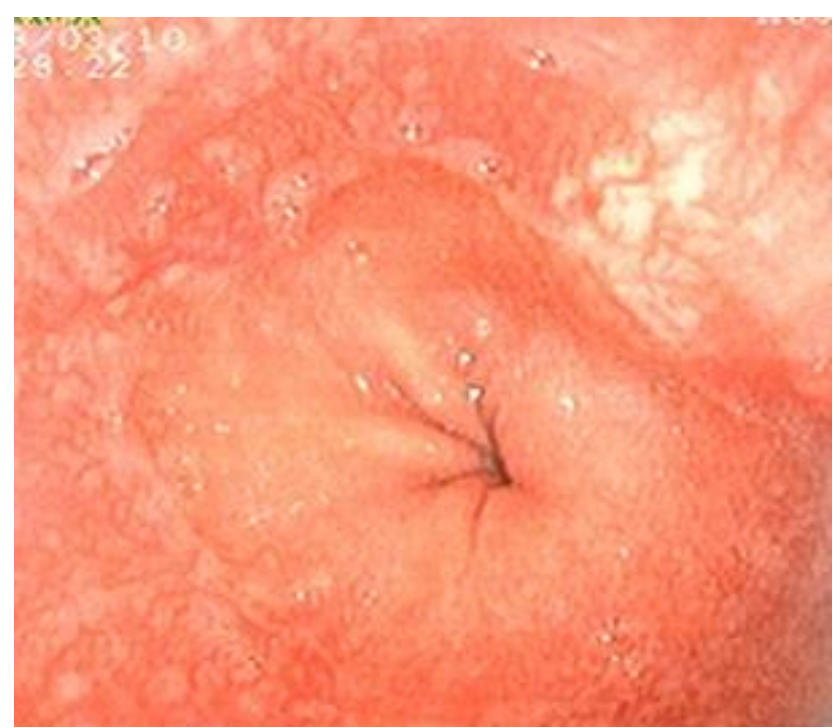

Fig. 3: Short Segment Barretts

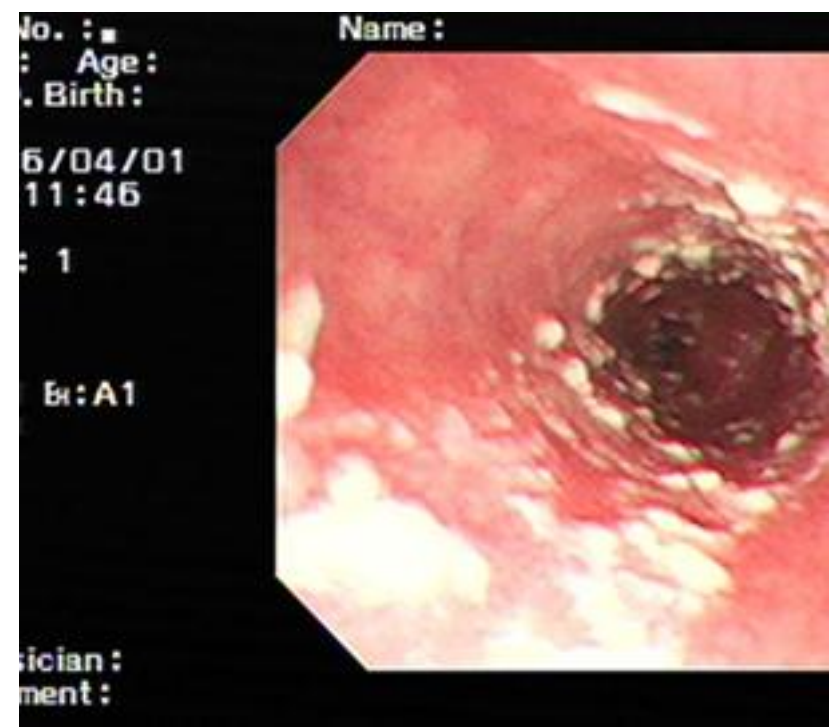

Fig. 4: Candidial Oesophagitis 


\section{Discussion}

In a study by $t$ ramdas et al, (2003) among 50 pts, they found $1 \mathrm{pt}$ of growth and epistaxis as a complication in $4 \%$ cases of pts undergoing tne, which is similar to our study. On vas atar et all found similar results as we found in our study as long as the over all discomfort related to both procedures the and toe is concerned. Stroppa et al (2008)reported that tne without sedation was better accepted than conventional toe in $30 \mathrm{pts}$, who underwent both procedures on consecutive days.

\section{Conclusion}

TNE is safe, easy and low cost procedure with better patient comfort and better patient tolerability and acceptability. It also alleviates the diagnostic delay. It is good tool in the hands of otolaryngologists to diagnose various diseases of esophagus in early stage. There is no gaging or retching in this procedure. Sedation is not required in TNE. It is a convenient office based procedure.

\section{Conflict of Interest: None.}

\section{References}

1. Kaufman JA, Belafsky PC, Bach KK. prevalence of oesophagitis in patients with ph documented laryngopharyngeal rflux. Laryngoscope 2002;112(9):16061609.
2. Aviv JE, Takoudes T, Ma G. Office based oesophagoscopy: a preliminary report. Otolaryngol head neck surg 2001;125:170175.

3. Belafsky PC. Office endoscopy for laryngologist / bronchoesophagologist. Current opin Otolaryngol Head and neck surg 2002,10:467-471.

4. Postma GN, Amin MR,Cimpson CB. Office procedures for oesophagus. Ear nose throat J 2004;83(7- 2):17-21.

5. Fein M, Ritter MP, DeMeester TR. Role of lower oesophageal sphincter and hiatus hernia in the pathogenesis of gastroesophageal reflux disease. J Gastrointest Surg 1999;3:405-410.

6. Gordon C, Kang JY, Neild PJ. The role of hiatus hernia on gastroesophageal reflux disease. Aliment Pharmacol Ther 2004;20:719-732.

7. Barrett NR, Chronic peptic ulcer of the oesophagus and oesophagitis. Br J Surj 1950;38:175-182. Barrett NR. The lower oesophagus lined by columner epithelium. Surg 1957;41:881-894.

8. Boyce HW. Barrett oesophagus:endoscopic findings and what to biopsy. J Clin gastroenterol 2003;36(5):S6-S18.

9. $\quad$ Spechler SJ.Barrett' oesophagus. N Engl J Med 2002;346:836842.

10. Postma GN, Cohen JT, Belafsky PC. Transnasal oesophagoscopy: revisted (over 700 consecutive cases) Laryngscope 2005;115(2):321-323.

How to cite this article: Gupta MK, Upadhya M, Bihari A, Transnasal oesophagoscopy - A study of its advantages and limitations. Indian $J$ Anat Surg Head Neck Brain 2018;5(1):26-28. 